Vol. 3, n² | 1999

Varia

\title{
Le régicide en République
}

Sadi Carnot, 24 juin 1894 - Paul Doumer, 6 mai 1932

Karelle Vincent

\section{OpenEdition}

Journals

Édition électronique

URL : https://journals.openedition.org/chs/891

DOI : $10.4000 /$ chs.891

ISSN : 1663-4837

Éditeur

Librairie Droz

\section{Édition imprimée}

Date de publication : 1 juin 1999

Pagination : 73-93

ISBN : 2-600-00398-3

ISSN : 1422-0857

\section{Référence électronique}

Karelle Vincent, «Le régicide en République », Crime, Histoire \& Sociétés / Crime, History \& Societies [En ligne], Vol. 3, n² | 1999, mis en ligne le 03 avril 2009, consulté le 22 mars 2022. URL : http://

journals.openedition.org/chs/891 ; DOI : https://doi.org/10.4000/chs.891 


\title{
Le régicide en République \\ Sadi Carnot, 24 juin 1894 - Paul Doumer, 6 mai 1932
}

Karelle Vincent ${ }^{1}$

\begin{abstract}
A la lumière des morts tragiques de Sadi Carnot et de Paul Doumer, l'assassinat du président de la République sous la Troisième République a eu un impact variable dans la société. Érigée en véritable martyre républicain, la mort de Carnot, longtemps commémorée, s'oppose à la faible résonance de celle de Doumer. C'est, au delà des facteurs contextuels, que la signification globale du crime aux yeux du corps social s'est, en 38 ans, considérablement modifiée. Du régicide de 1894 au crime politique de 1932, la signification de l'assassinat du président de la République ne dépend pas de la définition technique du poste présidentiel mais du rapport plus large des individus au politique.
\end{abstract}

In the light of the tragic deaths of Sadi Carnot and Paul Doumer, it becomes clear that the impact, on French society under the Third Republic, of the assassination of a president varied. Held up as a republican form of martyrdom, Carnot's death, long commemorated, contrasts with the little impact of Doumer's assassination. One reason for this is that, above and beyond contextual factors, in 38 years, the global meaning of such a murder had changed considerably in the public mind. From regicide in 1894 to a political crime in 1932, the meaning of a presidential assassination does not depend on the technical definition of the office of president but on the more general relation of citizens to politics.

T e régicide, entendu au sens de l'attentat envers le souverain, est, bien au delà de son aspect anecdotique, un événement capital. Quelle plus grande atteinte à l'ordre en effet que ce crime attaquant directement l'État, le blessant dans sa chair à travers le corps de celui qui le représente, le symbolise, voire l'incarne? Il peut à juste titre être considéré comme une des plus grandes agressions auxquelles le pouvoir est susceptible d'être confronté. Le poids de la personnalité visée, poids politique mais surtout symbolique, lui confère qui plus est une charge émotionnelle considérable. D'où, lorsqu'il se produit, une publicité et une résonance exceptionnelles.

On comprend dès lors à quel point le régicide, fait historiquement daté, jouit d'un statut particulier dans l'histoire. Événement traumatique, il fascine, marque, interpelle, comme en témoigne l'abondante littérature qui lui est consacrée. Jusqu'à il y a peu essentiellement axée sur la question des responsabilités de l'attentat et de l'éventualité d'un complot, elle s'oriente désormais vers l'étude des représentations

1 Doctorante en histoire à l'Université de Bourgogne, Karelle Vincent prépare actuellement une thèse sur «Le régicide de Ravaillac à Gorguloff : perceptions et représentations », sous la direction de JeanMarc Berlière. 
de l'événement. À l'ouvrage fondateur de Roland Mousnier ont notamment succédé les travaux de Pierre Rétat et de Dale Van Kley ${ }^{2}$.

Mais, au delà de ces études ponctuelles, le régicide n'a jamais été étudié en tant que crime générique, transcendant une large période. Les récents développements sur la violence politique l'intègrent, lorsqu'ils ne l'occultent pas, dans la catégorie plus vaste des crimes politiques ${ }^{3}$. C'est oublier toute la spécificité du crime qui, loin d'être réductible à l'aspect strictement matériel, technique qu'évoque son étymologie - rex caedere, littéralement «tuer le roi »-peut être défini par la charge signifiante dont il est porteur. À travers l'atteinte au souverain, le régicide est avant tout l'atteinte au symbole - symbole de l'autorité certes, mais plus largement symbole politique. En ce qui concerne la France, le roi d'Ancien Régime, le monarque constitutionnel, l'empereur et le président de la République ont ceci de commun qu'ils représentent les valeurs sur lesquelles se fonde l'État, et qu'ils occupent une place à part dans le jeu institutionnel, figure qui rassemble, unit la multitude de citoyens dans un grand collectif transcendant: peuple ou nation. Une étude sur long terme du régicide à travers les régimes politiques, qui serait riche en enseignements sur les imaginaires politiques, reste donc à faire 4 .

Dans cette perspective, l'assassinat du président de la République, en France, sous la Troisième République peut être considéré comme un objet historique intéressant. Pourtant, les études, même ponctuelles, qui lui sont consacrées sont rares. Le centenaire de la mort de Sadi Carnot en 1994 a certes donné lieu à un regain d'intérêt pour l'événement, mais bien peu d'écrits émanent du milieu historique ${ }^{5}$. Quant à l'assassinat de Paul Doumer, il n'a à notre connaissance donné lieu qu'à une seule recherche, jusqu'alors non publiée ${ }^{6}$.

Ce long désintérêt pour le meurtre du président de la République, d'autant plus flagrant si l'on considère l'abondance des écrits relatifs à la mort du roi, s'explique sans doute par la faiblesse des attributions qui sont les siennes sous la Troisième République, par son rôle délibérément restreint sur la scène politique. Désintérêt qui ne nous semble pas légitime. Représentant le principe d'autorité ${ }^{7}$, gardien de la constitution, au-dessus des querelles politiques et des intérêts partisans, c'est justement parce que le président remplit une fonction essentiellement symbolique que sa mort revêt une dimension particulière.

Aux débuts de son histoire, la Troisième République s'est pourtant crue, en raison même de cet effacement de l'exécutif, à l'abri du régicide. «Il n'y a de complots, de conspirations organisés par de petits groupes de sectaires ayant pour but

2 Mousnier (1964); Rétat (1980); Van Kley (1983).

3 Cf. Ford (1990). Ce phénomène se retrouve dans le colloque «Regicide et meurtre de l'homme d'État. Histoires, formes, représentations » qui s'est déroulé à Paris en novembre 1995: sur un total de 19 interventions, un peu plus d'un tiers étaient consacrées à la question du régicide et du meurtre du chef d'État, tandis que les 12 autres traitaient de la problématique plus vaste de l'assassinat politique. L'ouvrage publié sous la direction de P. Braud (1993) ne traite en revanche pas du régicide.

4 C'est l'ambition de notre travail de doctorat initié en 1996 sous la direction de Jean-Marc Berlière.

5 On peut toutefois retenir l'étude de Patrick Harismendy qui s'est interrogé sur les modalités d'affirmation de l'ordre républicain face à l'attentat, Harismendy (1994).

- La question de la lecture contemporaine du crime comme complot (communiste ou fasciste) ou comme acte individuel a été traitée par Couré Sophie et Monier Frédéric (1995). Nous tenons par ailleurs à remercier ici Sophie Couuré et Frédéric Monier de nous avoir fait parvenir le texte dactylographié de leur intervention, qui nous a été d'une grande aide.

7 Cf. Lacroix, Lagroye (1992). 
des régicides que dans les pays où il n'y a pas d'opinion publique. C'est là le châtiment des gouvernements autocratiques (...). Dans un pareil état de choses, les opposants ne s'attaquent pas à une institution, ils s'attaquent à l'homme (...). Personne ne pense à tuer la reine d'Angleterre ni M. Grévy ${ }^{8}$. On tue César, on tue les czars. Ces meurtres politiques sont la conséquence de toutes les dictatures écrit La Lanterne du 16 mars 1881. Les faits lui opposeront quelques années plus tard un sanglant démenti : le 24 juin 1894, Sadi Carnot, venu assister à l'Exposition Universelle de Lyon, meurt poignardé par un jeune anarchiste italien, Santo Caserio ${ }^{9}$. Le 6 mai 1932, c'est au tour de Paul Doumer de succomber aux coups de revolver que lui a infligé un émigré russe, Paul Gorguloff. Par deux fois sous la Troisième République, le président périra victime d'un attentat.

Quelle signification peut revêtir le meurtre du président de la République sous la Troisième République, ce régime qui se fonde sur l'idée de souveraineté populaire et de délégation, qui se construit en opposition à toute incarnation personnelle du pouvoir, instaurant ainsi un nouveau rapport au politique ${ }^{10}$ ? C'est ce que nous allons tenter de saisir à travers la mise en perspective des représentations contemporaines des assassinats de Sadi Carnot et de Paul Doumer. Nous nous interrogerons sur la manière dont l'événement est narré, évoqué, sur les réactions qu'il a suscitées, l'impact qu'il a eu sur la société. Nous tenterons ainsi de restituer l'image que se sont fait les contemporains du crime et du criminel et surtout de comprendre, à travers ses permanences et ses évolutions, les conditions de sa formation: dépend-elle des formes institutionnelles et de l'idéologie revendiquée par le régime? Est-elle tributaire de l'appartenance politique et/ou sociale des individus?... A travers la réponse à ces interrogations c'est une partie de l'histoire de la Troisième République qui nous est révélée. La perception du meurtre par les milieux institutionnels dit la façon dont le régime définit et construit son identité; parallèlement, à travers le rapport des contemporains au crime se lit leur rapport à la Troisième République.

\section{I. - CRIME ET SOCIÉTÉ: UN IMPACT DIFFÉRENCIÉ}

En dépit de cet invariant qui constitue la définition même de l'événement ( $l$ 'assassinat du président de la République), force est de constater que celui-ci a été res-

8 Alors président de la République en France.

- Il est également connu sous le nom de Sante Caserio.

10 Cf. la crise du 16 mai 1877, événement fondateur du régime parlementaire. Les lois constitutionnelles avaient conféré des pouvoirs importants au président de la République, chef des armées, détenteur du pouvoir exécutif et du droit de dissolution. Le conflit qui opposait le président Mac Mahon à la chambre des députés en mai 1877 conduisit ce premier à la dissoudre: celle-ci, en majorité républicaine, refusait de voter la confiance au gouvernement conservateur formé par le duc de Broglie. Celui-ci avait êté nommé à la présidence du Conseil après que Mac Mahon ait acculé Jules Simon, républicain modéré, à démissionner, le 16 mai. L'échec de cette mancuvre, les nouvelles élections ayant reconduit à la Chambre une majorité républicaine, amena le président à se soumettre et à accepter de former un ministère de centre-gauche. C'était là l'échec de la tentative d'interprétation présidentielle des lois constitutionnelles. Son message aux chambres confirmant sa soumission et stipulant que «l'exercice du droit de dissolution (...) ne saurait être érigé en système de gouvernement» et que «la constitution de 1875 a fondé une République parlementaire» est un des textes fondateurs de la Troisième République en tant que régime parlementaire. Le droit de dissolution ne sera plus jamais utilisé par les présidents qui se cantonneront à un rôle de représentation, les gouvernements n'étant désormais plus responsables que devant les Chambres. 
senti très différemment en 1894 et en 1932. Plusieurs éléments témoignent en effet que l'impact du crime sur la société a été beaucoup plus fort en 1894.

La construction de l'événement, tout d'abord. Pendant plus de deux mois, l'assassinat de Sadi Carnot et son corollaire, "l'affaire Caserio», occuperont les premières pages des journaux. Des rubriques quotidiennes seront même créées: Le Petit Dauphinois Républicain intitule ainsi la sienne «L'assassin Caserio». La mobilisation des journaux ne passe pas seulement par les mots, mais aussi par les symboles: nombre d'entre eux bordent au lendemain du crime leur édition de noir, pour signifier leur participation au deuil. À cette surmédiatisation dans la presse quotidienne s'ajoute la mobilisation d'autres moyens d'information, comme cette affiche de grand format, placardée sur les murs de Paris et offrant au passant le résumé des audiences du procès Caserio, agrémenté de quelques croquis et commentaires hostiles au jeune anarchiste ${ }^{11}$. La profusion des articles, des poèmes, des dessins et gravures consacrés à l'événement témoignent ainsi de sa résonance exceptionnelle.

Sur ce point, la France de 1932 contraste singulièrement avec celle de 1894. À une époque où naissent et se développent d'autres relais d'information, propices à assurer une plus grande diffusion à l'événement, le crime mobilise moins l'ensemble des médias. Certes, Tardieu, alors président du Conseil, recourt à la TSF ${ }^{12}$ afin d'assurer la transmission de la cérémonie religieuse et des discours aux obsèques de Doumer. Mais le support écrit, alors prédominant, réserve moins de place à l'affaire. Si la nouvelle de l'attentat fait la «une» de nombreux journaux (les trois premières pages du journal Le Temps du 8 mai 1932 lui sont par exemple entièrement consacrées), très vite celui-ci n'occupe plus la place centrale de l'information. C'est le résultat des élections législatives qui tient toute la première page du Figaro du 8 et du 9 mai et du Temps du 10 mai. Hormis un intérêt pour les funérailles du défunt, l'affaire et ses développements seront relégués dans quelques colonnes annexes en première, seconde ou troisième page.

À une moindre publicisation de l'événement en 1932, une moindre mobilisation des journaux pour le deuil (seul le Journal Officiel borde son édition de noir), s'ajoute une moindre mobilisation des individus. Dans les deux cas pourtant, la mise en scène par la presse des réactions de la population à la nouvelle de la mort du président est identique, et s'ordonne autour des mêmes thèmes: l'incrédulité, la recherche fébrile d'information, la réprobation, la colère d'une foule survoltée qui réclame justice, puis la tristesse et l'émotion; le champ lexical du nombre et de la diversité des origines sociales et géographiques des individus que l'événement bouleverse; l'intensité de cette mobilisation enfin, dans le temps du quotidien (le crime constituant l'objet unique et central des conversations; les signes du deuil s'affichant spontanément au domicile des particuliers), ainsi qu'à l'occasion des manifestations du deuil (le défilé de la foule devant la dépouille du défunt exposée à l'Elysée, sa présence émue et massive aux obsèques) et de l'exécution de l'assassin. Mais ce sont les rapports de police qui, en contrepoint des récits journalistiques, nous informent sur la réalité de la perception de l'événement par la population, venant confirmer le plus grand impact du crime en 1894. L'effervescence est réelle ${ }^{13}$. Rien de tel, en revanche, en

$\because$ APP (Archives de la Préfecture de Police) Ba 996.

12 Ce terme, abréviation de «télégraphie sans fil», désigne par extension la radio.

13 "Hier soir la foule était considérable sur le boulevard Saint-Michel. Les terrasses des cafés étaient bondées de consommateurs. On s'arrachait les journaux du soir qu'on lisait à la clarté des becs de gaz 
1932, où l'émotion existe, certes, mais en moins marquée, moins intense. En témoigne également l'explosion de haine xénophobe qui se manifestera en 1894 à l'encontre des Italiens, jugés responsables du crime commis par leur compatriote, et qui aboutira parfois à de véritables pogroms, notamment dans les villes de Grenoble, Marseille, Avignon, Chambéry, Nancy et la région lyonnaise, poussant ainsi de nombreux travailleurs transalpins à réclamer leur rapatriement. Climat apocalyptique dans ces villes en proie aux exactions xénophobes qui, deux ans après, reste encore présent dans les esprits: "On vivrait cent ans qu'il serait impossible d'oublier tout cela», peut-on lire en 1896 dans Les Nouvelles du Soir ${ }^{14}$. Les réactions sont - heureusement - nettement plus mesurées en 1932 où, malgré les mesures d'ordre prises par le préfet de police afin d'assurer la sécurité de la communauté russe émigrée, aucune manifestation hostile n'a pu être recensée. Or, la colère, même illégitime, atteste à sa manière de la façon dont l'événement est vécu, plus ou moins affectivement, viscéralement.

Notons enfin qu'à l'inverse de la profusion des poèmes et des chants produits en 1894, la mort de Doumer ne semble pas avoir suscité de parole populaire, mais principalement des discours institutionnels et politiques.

Mais c'est peut-être l'inscription de l'événement dans la mémoire collective qui témoigne le mieux de l'impact qu'il a pu avoir. Déjà, aux funérailles de Carnot, des individus arrachent quelques fleurs aux couronnes exposées afin de les vendre comme souvenirs, à l'instar de nombreux camelots qui monnayent chansons, partitions, dessins, livrets. Plus d'un mois après l'enterrement, le gardien-chef du Panthéon doit demander des renforts pour repousser le public qui envahit le caveau ${ }^{15}$. Intérêt pour le défunt et, ce faisant, pour l'événement qui ne se dément pas puisque trois ans plus tard, ce sont au moins 11000 personnes qui ont défilé devant le tombeau ${ }^{16}$. Cette frénésie commémorative est relayée par l'État qui décrète le 24 juin 1895 journée de deuil national et qui, à plus long terme, multiplie les inaugurations de statues à la mémoire du défunt ou les visites au Panthéon (ainsi le président Émile Loubet poursuit-il encore, en 1905, la tradition des hommages annuels au Panthéon). Preuve de la marque de l'événement sur la société, le travail de mémoire fait en revanche singulièrement défaut pour Paul Doumer, dont le souvenir n'est plus guère célébré que dans le cercle restreint d'associations particulières ${ }^{17}$.

Comment expliquer une telle différence? On pourrait avancer que, si la perception du crime dépend de la fonction visée, elle est également tributaire de l'aura de son titulaire; et sur ce point, il est vrai que la figure de Carnot est nettement plus mobilisatrice que celle de Doumer. En raison de la durée du mandat respectif des victimes, tout d'abord. À son poste depuis sept ans, Carnot avait eu le temps d'occuper l'espace de la fonction présidentielle, de s'imposer comme un personnage familier, de se constituer en «repère». Doumer quant à lui n'était au pouvoir que

sur le boulevard même. L'indignation était unanime...». Rapport du commissaire de police du quartier Saint-Michel en date du 26 juin 1894, APP Ba 995.

«Les renseignements que l'on a recueillis dans différents milieux permettent d'affirmer que la mort de M. le président a péniblement affecté tout le public parisien (...).» Rapport du commissaire de police Roy du 25 juin 1894, APP Ba 995.

Les Nouvelles du Soir du 9 mars 1896, cité in Milza (1993, p. 118). 
depuis un an; en ce sens il n'avait pas encore réussi à s'ancrer au sein de la population, et n'avait pas bénéficié de cet avantage que la durée confère, de cette force de l'habitude qui se transforme progressivement en attachement. Qui plus est, loin d'être, comme le veut la philosophie républicaine, «le plus impersonnel des chefs d'État», Carnot jouissait d'une popularité notable, qui a sans aucun doute joué sur la perception de son assassinat. Véritable rassembleur (il participa fortement à la politique d'apaisement avec l'Église) ${ }^{18}$, il avait en outre introduit une nouvelle pratique du métier présidentiel; jusqu'alors considérablement limité par la «constitution Grévy ${ }^{19}$, le rapprochement de la présidence de la République avec le peuple ${ }^{20}$ avait été l'une des dominantes du mandat de Carnot qui, par la diffusion de ses portraits à l'échelon national et la multiplication de ses voyages en province, destinés à ancrer la République dans les mœurs en pleine crise boulangiste, se donnait à voir, rendait possible un rapport personnalisé avec la population ${ }^{21}$. D'où une relation plus affective avec la présidence de la République et, ce faisant, déterminant pour une large part la signification du crime. Rien de tel en revanche pour Doumer, que les récentes conditions de son élection ne prédisposaient pas à représenter en rassembleur, et dont l'austérité et la froideur ne suscitaient guère la sympathie et l'attachement ${ }^{22}$.

Mais ce type d'explication n'est pas suffisant. De fait, si le poids du crime est moindre en 1932 par rapport à 1894 , c'est d'abord principalement en raison des motivations de l'assassin et du contexte dans lequel il est survenu, mais aussi - et surtout - parce que la signification que revêt l'assassinat du président de la République aux yeux des médias et des divers acteurs sociaux a elle-même évolué.

\section{II. - DE LA SAUVEGARDE DE LA RÉPUBLIQUE A LA BATAILLE ELECTORALISTE}

L'attentat de 1894, parce qu'il se veut explicitement un acte de propagande anarchiste (Caserio déclare avoir tué Sadi Carnot parce qu'il avait refusé la grâce de Vaillant), renvoie à une crise endogène à laquelle la France se trouve confrontée depuis plus de deux ans ${ }^{23}$. Il s'intègre en effet dans la multiplication des attentats

18 Cf. Harismendy (1995, p. 343 et s).

19 La «constitution Grévy » désigne la coutume politique inaugurée par Jules Grévy, successeur de Mac Mahon, quant aux prérogatives et à la pratique de la fonction présidentielle sous la Troisième République. Celui-ci s'était engagé devant les chambres de faire en sorte qu'il n'y ait, au lendemain de la crise du 16 mai 1877 , plus aucun conflit entre le président et la majorité de l'Assemblée. Il fixera la tradition d'un effacement de la présidence au profit du parlement.

20 Par exemple, même si les lois constitutionnelles de 1875 n'établissaient aucune réglementation de l'appel présidentiel au peuple, celui-ci se trouvait condamné de facto depuis la crise de mai 1877 . Cf. Lehingue (1992, p. 124-125).

21 Cf. Mariot (1995).

22 Son élection à la présidence de la République en 1931, symbole du désaveu par la droite de la politique de conciliation de Briand vis-à-vis de l'Allemagne, avait en effet suscité une forte hostilité de la gauche et de l'extrême gauche.

23 Le 9 décembre 1893, Vaillant, un jeune anarchiste, jeta une bombe dans la chambre des députés. La sévérité du verdict - Vaillant fut condamné à mort bien qu'il n'y eut aucun tué - fut à la hauteur de la menace perçue par le pouvoir. Carnot refusa de lui accorder sa grâce, pourtant demandée par certains députés eux-mêmes. 
anarchistes qui, depuis les «événements de Clichy » ${ }^{24}$, n'ont cessé d'ensanglanter la République. Survenant dans un contexte de psychose collective entretenue par la presse et accentuée par l'impuissance du régime à prévenir et empêcher les attentats, on comprend dès lors à quel point il a pu mobiliser l'ensemble du corps social; véritable apothéose de la vague terroriste, il réveille toutes les tensions latentes, les exacerbe et, parce qu'il renvoie aux peurs de chacun, l'assassinat de Carnot est vivement ressenti par la population. Par ailleurs, les rapports de police au lendemain du crime attestent de la crainte d'un nouvel attentat, crainte qui ne fera que se renforcer au fil des jours, sous le poids des nouvelles rapportées par la presse; dès le 25 juin, on signale que Lyon serait en état de siège - nouvelle vite démentie par les autorités ${ }^{25}$. Chaque jour, les journaux relatent les arrestations de «dangereux anarchistes », voire colportent des rumeurs alarmantes, comme Le Nouvelliste de Lyon qui certifie que la voiture cellulaire transportant Caserio aurait été attaquée par cinq individus armés de revolvers, finalement mis en fuite par les forces de l'ordre ${ }^{26}$.

A contrario, les motivations de Gorguloff ne rejoignent pas les préoccupations principales de la société française de 1932: l'assassin déclare lors de son premier interrogatoire qu'il souhaitait, par son acte, amener la France à déclarer la guerre à la Russie. Sujet sur lequel la population française, davantage préoccupée par les premières manifestations de la crise économique ou par le développement des ligues factieuses, n'est pas mobilisée a priori.

Si l'adéquation des mobiles de l'assassin avec les préoccupations de la population au moment des faits a déterminé pour partie l'impact de l'événement, celui-ci a également dépendu du réinvestissement qui en a été fait par le régime. Alors que la mort de Carnot a été représentée à l'époque comme un sacrifice républicain, celle de Doumer n'a donné lieu qu'à une réutilisation partisane du meurtre, ce qui explique l'échec d'une entreprise mobilisatrice et fédératrice.

Inspiré par la philosophie libertaire, l'assassinat de Sadi Carnot marque la remise en cause de la légitimité du régime. Or, l'acte de Caserio est d'autant plus porteur de désordre qu'il s'attaque à une République fragilisée et incertaine. Régime encore jeune et controversé, comme l'avait montré la récente crise boulangiste ${ }^{27}$, elle est

24 Le $1^{\text {es }}$ mai 1891 trois manifestants anarchistes, pourtant initialement pacifiques, furent poursuivis et brutalement arrêtés à Clichy par Guilhem, un commissaire de police zélé et désireux de se distinguer par un coup d'éclat. Le caractère abusif de l'arrestation, les brutalités policières dont ils furent victimes (telles que l'on dut attendre avant de pouvoir les présenter au parquet) et enfin la sévérité du verdict, condamnant deux des accusés à 5 et 3 ans d'emprisonnement furent ressentis comme une grave injustice par les milieux libertaires. Ils suscitèrent une volonté de vengeance qui allait être à l'origine des premiers attentats terroristes. Le 11 mars 1892, une bombe détruit l'immeuble où loge le président de la cour d'Assises Benoît, ayant dirigé les débats du procès des anarchistes de Clichy; le 27 mars, l'immeuble habité par le substitut Bulot, qui avait requis la peine capitale contre les prévenus est visé à son tour. L'épidémie terroriste ne devait cesser qu'après l'acte de Caserio. Pour plus de détails, cf. Maitron (1992, p. 206-250).

Cf. Le Petit Dauphinois du 25 juin 1894.

26 Le Nouvelliste de Lyon du 6 août 1894.

27 Le mouvement boulangiste (du nom de son leader, le général Boulanger), cristallise, de 1887 à 1889 , l'opposition à la Republique parlementaire. Nationaliste, il regroupe des individus venus de l'extrême gauche du parti radical et de l'extrême droite monarchiste et bonapartiste qui tous souhaitent la fin de la république parlementaire au profit de l'établissement d'un régime fort. Il rencontrera un succès notable dans l'opinion publique, notamment auprès du milieu ouvrier, succès dont le point culminant sera l'élection triomphale, le 27 janvier 1889, du général Boulanger à Paris. Le soir même, ses partisans l'enjoignent à marcher sur l'Elysée, mais il refusera le coup d'État. Inculpé de complot devant la haute Cour, il s'enfuit en Belgique où il se suicide. C'est la fin de l'épisode boulangiste. 
alors confrontée à la déstructuration du lien social républicain, au mécontentement de la population qui la juge discréditée et corrompue (le scandale de Panama est encore présent dans les consciences) ${ }^{28}$, incapable de répondre à la question sociale autrement que par la force (on se rappelle ici le massacre de Fourmies) ${ }^{29}$. Dans cette situation, les autorités vont réinvestir le crime de telle sorte qu'il puisse unir la population autour du régime. La mort de Carnot va ainsi être présentée comme un sacrifice s'intégrant dans un combat pour la République qu'il est nécessaire de poursuivre, et c'est ce sens extrêmement «lourd » conféré à l'événement qui lui assure une résonance exceptionnelle.

Très vite, les éloges funèbres, loin de se limiter à de simples panégyriques, vont s'affirmer comme de véritables discours de propagande républicaine. Ceux-ci vont s'efforcer de faire de Carnot le symbole du combat pour la République. Par le rappel fréquent de ses origines, tout d'abord. Carnot est en effet le descendant d'une longue lignée républicaine; très tôt, ses ancêtres se sont illustrés par leur engagement politique, comme Lazare, président de la Convention en 1794, ou encore son père Hippolyte qui participa à l'insurrection du peuple parisien menée par les députés du 2 au 4 septembre 1851, et qui, député sous l'Empire, refusa toujours de prêter serment. À travers l'histoire des Carnot, de leur foi et leur dévouement à l'idée républicaine, c'est l'histoire tourmentée de la République qui est contée, c'est la force de l'idéal qui est signifiée.

La vie de Carnot elle-même s'intègre dans la continuité de ce combat pour la liberté entamé il y a plus d'un siècle. Son engagement passe en premier lieu par la stricte adéquation de son existence aux valeurs défendues. On loue son attachement à la famille, cette famille perçue par la République comme le fondement de l'État, le «creuset de la conscience nationale $»^{30}$; on le définit comme un "grand citoyen », un "vrai Français " ${ }^{31}$, car patriote. Ces vertus citoyennes, à valeur d'exemple, se doublent de vertus politiques, puisque Carnot a toujours exercé sa fonction présidentielle selon les strictes règles de la philosophie républicaine. C'est, à ce propos, la "constitutionnalité » du président défunt qui est le plus souvent célébrée, c'est-àdire sa conformation aux stricts engagements de la «Constitution Grévy», visant à l'effacement de l'exécutif, ainsi que la «représentativité » qu'il a su donner à la présidence de la République, en restant proche de la population, à l'écoute des humbles.

28 Révélé en 1892, ce scandale politico-financier est un des plus graves qu'a connu la Troisième République. Il impliquait des députés soupçonnés d'avoir touché, en échange de leur bienveillance, des pots-de-vin allant jusqu'à 370000 francs de la part de la compagnie du canal de Panama, dont le président de la chambre Floquet. Le président du Conseil Émile Loubet fut accusé d'avoir tenté d'entraver le cours de la justice. Au total, 104 parlementaires furent traines devant la cour d'Assises de la Seine dans le procès en corruption de fonctionnaires et de parlementaires qui se termina le 21 mars 1893. Tous, faute de preuve, ou en vertu des circonstances atténuantes, furent disculpés, sauf l'ancien ministre des Travaux Publics Bähaut qui, ayant reconnu les faits, fut condamné à 5 ans de prison ferme. Malgré ce verdict, le corps politique était discrédité et ce scandale fit resurgir un sentiment d'antiparlementarisme.

29 En 1891, la population ouvrière de Fourmies défile à l'occasion du $1^{\text {er }}$ Mai, « fête des travailleurs ", jour de grève. Sans raison apparente, la troupe tire, sans sommation. Dix personnes furent tuées, dont une jeune fille de 18 ans. Ce drame, lourd de conséquence pour le régime, consacra une rupture profonde entre la République et le peuple ouvrier. Dès lors, le drapeau rouge remplaça le drapeau tricolore dans les manifestations ouvrières et les chants de la Carmagnole voire de l'Internationale se substituèrent à la Marseillaise ; voir Noiriel (1986, p. 105-106).

30 L'expression est de Michelle Perrot (1987, p. 105).

31 L'illustration du 30 juin 1894. 
Enfin, Carnot est présenté comme le sauveur de la République ${ }^{32}$, celui qui lui a permis de surmonter l'épisode boulangiste et la crise de Panama et qui a contribué, par ses voyages en province, à l'ancrer dans les mœurs ${ }^{33}$.

Consécration d'une vie toute entière gouvernée par le don de soi, la mort de Carnot est alors présentée comme un sacrifice pour la République; une véritable martyrologie républicaine se construit autour du défunt, tant il est vrai que pour beaucoup, «le crime de Caserio a donné aux mérites du président Carnot la consécration du martyre ${ }^{34}$. Martyre qui trouve sa source dans le courage de Carnot face à la mort, courage d'autant plus grand que celui-ci a souffert de façon très vive, chose intolérable en ces temps de révolution hygiéniste, et dans sa dignité: lors de son agonie, il ne prononcera aucune parole de récrimination contre son meurtrier. Mais, tant il est vrai qu'un martyr est quelqu'un qui souffre et qui meurt au nom de ses convictions, Carnot est avant tout le martyr de la cause républicaine. Il meurt en soldat: «Le président Carnot est tombé dans l'exercice de ses fonctions comme un soldat au champ d'honneur», déclare le président du Conseil Dupuy devant son cercueil. Soldat qui succombe, victime d'une guerre juste, la défense de la cause républicaine: Carnot «a donné à son pays sa vie même, car c'est pour la France et la République qu'il est mort ${ }^{35}$. C'est cet aspect martyrologique qui expliquera d'ailleurs les funérailles grandioses du 1er juillet, la mise en scène républicaine du deuil, et qui vaudra à Carnot de rejoindre son ancêtre Lazare au Panthéon ${ }^{36}$.

Les discours insistent sur la nécessité de poursuivre ce combat, ce qui induit l'oubli des dissensions, le regroupement de tous les Français autour du régime: le maire de Lyon, Gailleton, exhorte les citoyens, en «ce jour de deuil national et de terrible épreuve », à rester «serrés autour du drapeau de la République » et est, en ce sens, relayé par le discours journalistique ${ }^{37}$. Or, la gravité de l'enjeu, le contexte tendu dans lequel est survenu le crime, mais aussi les signes produits lors des obsèques de Carnot ont effectivement engendré une dynamique unitaire et mobilisatrice $^{38}$. La signification extrêmement lourde conférée à l'assassinat explique son impact exceptionnel et son inscription dans la mémoire collective.

32 Sans qu'il dépasse le rôle que les institutions coutumières de la Troisième République lui impartissaient; on souligne qu'il a agi grâce à la seule marge de manœuvre qui lui était laissée par la constitution Grévy: le choix du président du Conseil.

33 «Puis, porté d'une manière imprévue à la magistrature suprême, il travaille pendant près de 7 ans au bien du pays, il s'applique à faire aimer la République, en désarmant par son sourire aimable et loyal jusqu'aux plus profondes rancunes, en se prodiguant à tous dans un voyage sans fin »; discours de Challemel-Lacour, président du Sénat, au Panthéon le $1^{\text {ex }}$ juillet 1894, reproduit in Lavialle de Lameillère (1895, p. 104).

34 Bertol (1899, p. 175).

35 Discours de Charles Dupuy, président du Conseil, reproduit in Le Petit Dauphinois du 2 juillet 1894.

36 «La patrie a fait au grand et doux martyr de splendides funérailles officielles » Le Petit Journal du 2 juillet 1894. «La patrie est une mère qui sait, au delà de la mort, armer et consacrer l'impérissable souvenir de ceux de ses fils qui ont vécu, qui ont souffert, qui sont morts pour ellen; discours de M. Cousteau, maire de Bordeaux, reproduit in Monument de Carnot à Bordeaux... (1896).

37 Proclamation placardée dans toute la ville de Lyon au lendemain de l'attentat. Archives Départementales du Rhône, dossier 4 M 314 .

38 Le drapeau tricolore, omniprésent, rappelle ainsi à tous leur appartenance à un cadre à la fois géographique (le territoire français) et politique (la République); il réfère également au passé commun, puisque témoin de tant de luttes, externes (la guerre contre la Prusse est encore présente dans les consciences) comme internes (le choc des révolutions). Le Panthéon ne résume-t-il pas d'ailleurs aussi toute cette mémoire commune, tant il est vrai qu'il est, au travers de ceux qui ont su marquer l'histoire de la patrie, la mémoire de la nation? 
C'est dans un contexte fort différent qu'est survenu le meurtre de Doumer. La République n'a plus besoin de martyrs, elle jouit depuis 1918 d'une reconnaissance sociale et politique. Par ailleurs, Gorguloff ne remet nullement en cause la forme des institutions.

Pourtant, se mettent en place des stratégies similaires à celles de 1894, propres à susciter une dynamique unitaire. Les éloges funèbres développent une image consensuelle et apolitique de la victime, dans laquelle chaque individu peut se reconnaître; à ce titre, les origines modestes de Doumer, ce «fils du peuple», sont mises en exergue par la quasi-totalité des discours, transformant le défunt en symbole de la réussite républicaine, et rappelant ainsi les possibilités offertes par le régime ${ }^{39}$. Comme Carnot, Doumer est défini par ses vertus civiques: à nouveau, on célèbre ce "grand citoyen», ce "grand Français " ${ }^{40}$, dont les vertus familiales se doublent d'un patriotisme si pur qu'il avait accepté sans défaillir la mort de ses fils des suites de la grande guerre: «Nul cœur plus déchiré n'a payé plus lourde dette envers la patrie avec plus de grandeur d'âme et de silencieuse souffrance ${ }^{41}$ puisque, comme il l'aurait dit lui-même à leurs obsèques, «la mort n'est rien quand elle est utile ${ }^{42}$. Caractérisé par son abnégation au service de la France, Doumer, comme Carnot, est mort en soldat, à son poste. À nouveau, les discours des instances officielles transforment sa mort en sacrifice, mais ici ce n'est pas d'un martyre républicain dont il s'agit: Doumer est «mort pour la France», pour la Patrie, et son sacrifice est mis en parallèle avec celui de ses enfants, réactivant ainsi le souvenir de la guerre. Cette mort, comme en 1894, doit fédérer, rassembler; Tardieu, Millerand et Reynaud appellent à une sorte d'union sacrée et les journaux de gouvernement, comme Le Temps, souhaitent faire de l'élection du successeur de Doumer «un geste d'unanimité exprimant une parfaite solidarité nationale ${ }^{43}$. Les autorités chercheront à exploiter dans ce sens les funérailles du défunt, en leur offrant la plus grande lisibilité possible: le convoi funèbre emprunte les grandes avenues de la capitale, au rythme d'une lenteur calculée. Il se donne à voir, revêt les signes de la nation (les drapeaux tricolores abondent), et cherche ainsi à rassembler.

Cette tentative unitaire a néanmoins échoué. Parce que, tout d'abord, le sens de certaines paroles a changé. En 1932, le thème d'union nationale ne fédère plụs l'ensemble des Français car il est un thème à connotation partisane. Notion accaparée par la droite depuis la formation du Bloc National au lendemain de la guerre ${ }^{44}$, elle était par ailleurs développée antérieurement à l'attentat par Tardieu, et ce encore la veille même de l'annonce du crime ${ }^{45}$. Après la mort de Doumer, l'appel à l'union sera repris principalement par les journaux de droite, comme Le Temps, Le Figaro ou encore Le Journal.

39 Discours prononcé par André Tardieu aux funérailles de Doumer, 13 mai 1932, reproduit in Journal officiel, Lois et décrets, 1932, p. 5010-5012.

40 Le Journal du 14 septembre 1932.

41 La fin tragique du président Paul Doumer... (1932, p. 52).

42 Villiers (1932, p. 3).

43 Paul Reynaud in L'Intransigeant du 8 mai 1932: «À la veille de la guerre, le sang de Jaurès a cimenté l'union sacrée. Puisse le sang de Paul Doumer avoir la même vertu !»; «Unanimité nécessaire », Le Temps du 9 mai 1932.

44 Cf. Rémond (1982, p. 184-185).

45 Il exposait ainsi ses idées dans un article du Figaro du 6 mai 1932 intitulé «Pour l'Union nationale». 
Qui plus est, ce thème coexiste avec une réutilisation partisane du meurtre, qui doit beaucoup au contexte dans lequel s'est produit le crime. L'attentat de Gorguloff survient en effet entre les deux tours des élections législatives, dans une atmosphère de fièvre électorale, d'oppositions politiques exacerbées, comme en témoignent les articles de presse extrêmement virulents qui précèdent l'attentat. Loin de calmer les oppositions, l'assassinat du président de la République va devenir un élément de la bataille électoraliste. Quelques heures après l'attentat, un communiqué du ministère de l'Intérieur affirme que Gorguloff est un provocateur soviétique, auteur d'une brochure marquée d'un emblème néo-bolchevique et porteur, lors de son arrestation, d'une carte de membre du Parti Communiste. Déclarations en parfaite contradiction avec les aveux de l'assassin et, surtout, avec les premiers éléments de l'enquête: aucune carte de membre du PC n'avait été trouvée sur Gorguloff et les reproductions ultérieures de l'insigne illustrant la brochure montrent que celui-ci n'offrait qu'une similitude très lointaine avec le sigle communiste. Cette lecture officielle du meurtre, pour laquelle on ne peut retenir l'hypothèse de la mésinformation ou de l'erreur, a visiblement été orchestrée par Tardieu afin de discréditer le Parti Communiste à la veille du second tour des législatives. Relayée par la presse de droite, la thèse du complot soviétique, à laquelle s'oppose une virulente contre-propagande communiste faisant état d'un complot gouvernemental impliquant Tardieu, le préfet de police Chiappe et les milieux russes blancs émigrés en France, disparaîtra au lendemain des élections ${ }^{46}$.

Loin de se référer uniquement à des points consensuels de l'idéologie républicaine et nationale, les discours funèbres s'intègrent également dans une entreprise partisane. Ceux-ci, sous couvert de la célébration du défunt, procèdent souvent à la légitimation d'un programme politique. À une époque où se tient la conférence du désarmement et où Jacomet représente la France à la commission des dépenses de défense nationale de Genève, on rappelle les propos élogieux de Doumer sur l'armée ${ }^{47} ;$ Le Temps quant à lui en profite pour justifier une politique d'apaisement doublée de vigilance à l'égard de l'Allemagne ${ }^{48}$, reprenant ainsi l'idée que le désarmement ne peut être accepté que si la sécurité de la France est assurée. Si l'on célèbre en Doumer le "démocrate " ${ }^{49}$, c'est par opposition au mouvement communiste et à l'essor du fascisme, deux constantes de l'idéologie de la «nouvelle droite» défendue par Tardieu. Le discours prononcé par ce dernier aux obsèques illustre particulièrement cette modification en profondeur de l'éloge funèbre, puisqu'il y développe une idéologie qui n'est pas l'idéologie républicaine, unitaire et consensuelle mais celle, partisane, d'un homme aux convictions particulières: en soulignant que Doumer n'avait pas «les dons du tribun, dont les masses subissent la puissance verbale», Tardieu opère une critique implicite du communisme et du socialisme, dont les récents succès aux élections l'inquiètent. Mieux, en ajoutant que, «durant la courte année qu'il occupa le siège présidentiel ", Doumer, "pour assurer le succès des solutions qu'il croyait sages, (...) n'hésitait pas à sortir des traditions et des

46 Cf. Couré, Monier (1995).

47 «Du jour où les fils de France cesseraient d'être des vaillants soldats, ils pourraient s'attendre à voir leur pays rayé de la carte du monde».

48 «Et, sur l'autre plan des antagonismes internationaux, il ne cessa non plus d'être un conseiller de sagesse, de loyauté, de modération. Paul Doumer fut, par excellence, le Français pacifique qui veut fonder la paix sur l'honnêteté», Le Temps du 8 mai 1932. 
rites ${ }^{50}$, il tente de légitimer sa propre philosophie politique, qu'il développera plus tard dans Le souverain captif, c'est-à-dire l'idée d'un renforcement des pouvoirs de l'exécutif par le biais de ceux du président de la République. On est bien loin ici de la célébration du modèle de la constitution Grévy.

\section{III. - L'ÉVOLUTION DE LA SIGNIFICATION DU MEURTRE: LA FIN DE L'EXCEPTIONNALITE DU CRIME?}

C'est également un tournant dans la lecture du crime qui se produit en 1932 et explique la résonance inégale des deux événements: si l'on s'attache aux représentations qui sont données du meurtre on s'aperçoit que la signification que revêt l'assassinat du président de la République dans l'absolu s'est considérablement modifiée.

On peut premièrement observer le passage, en 1932, de la lecture du meurtre comme régicide à ce que l'on pourrait qualifier de «régicide républicain». Si le crime de Caserio est perçu comme « un des plus grands crimes que l'histoire ait eu à flétrir $»^{51}$, c'est parce que celui-ci n'est pas tant jugé comme un simple «propagandiste par le fait ${ }^{52}$ que comme un régicide ${ }^{53}$. Immédiatement, tant dans la presse que dans les écrits populaires, les références au régicide abondent, que ce soit par la simple utilisation du terme pour définir l'assassin que par la mise en perspective de son crime avec les autres tentatives qu'a connue la France. Avec Carnot, «la République a son martyr, la République a son régicide»; au nom de Caserio se mêlent ceux de Fieschi et Orsini ${ }^{54}$.

Cette référence au régicide disparaît presque totalement en 1932. Seuls L'Ami du Peuple du 31 juillet et Le Journal du 14 septembre emploient ce qualificatif; le procureur Donat-Guigue fait lui aussi exception en déclarant que l'on «ne manquera pas de comparer Gorguloff à la longue série des régicides dont l'histoire a enregistré les sanglants exploits " ${ }^{55}$. En effet, lorsque le crime est mis en parallèle avec ses précédents historiques, il est intégré dans la lignée des attentats contre les présidents de la République: on évoque l'attentat de Caserio, mais également ceux commis à l'encontre de Loubet et de Millerand ${ }^{56}$. Il a ainsi perdu de sa force, de sa puissance évocatrice, de son exceptionnalité.

50 Il fait sans doute allusion à la tentative de Doumer d'interdire à Painlevé la formation d'un ministère de gauche en février 1932, et d'ainsi imposer ses choix au président du Conseil; tentative qui avorta en partie puisque, bien que Doumer, par respect de la tradition, ait dû s'incliner, Painlevé échoua. Il fut remplacé le 20 février par Tardieu qui procéda à la formation d'un ministère à droite.

51 Trilogie... (1897, p. 5).

52 Depuis son adoption officielle au Congrès International Socialiste Revolutionnaire de Londres de juillet 1881, l'action terroriste était considérée comme seul moyen de propagande efficace par les anarchistes car elle permettait de réveiller, par un acte d'éclat, les consciences de ceux qui, peinant tout le jour au travail, n'avaient guère le temps de se consacrer à la lecture des écrits libertaires ou à l'écoute de ses orateurs. On parlait à son sujet de «propagande par le fait ».

53 «C'est un fanatique vrai, non un malfaiteur de laboratoire, et son attentat est le régicide classique, le régicide antique et latin ", Gil Blas du 4 août 1894.

54 L'Estafette du 26 juin 1894. Fieschi, auteur de l'attenat manqué du 28 juillet 1835 contre le roi LouisPhilippe; Orsini est le responsable de celui dirigé à l'encontre de l'empereur Napoléon III le 4 janvier 1858.

55 La revue des grands procès, 1933 , tome 39 , Paris, p. 8.

56 Cf. Le Journal du 7 mai 1932, Le Temps du 8 mai 1932 et Le Figaro du 9 mai 1932. Le 30 mai 1905 Loubet avait échappé, rue de Rohan, à une bombe destinée au roi d'Espagne Alphonse XIII à sa 
Qu'est-ce qui détermine cette différence dans la représentation du crime? Dans certains cas, l'assimilation au régicide tient à sa classification par les criminologues. En cette fin de XIX ${ }^{\mathrm{e}}$ siècle où le savoir médical cherche à catégoriser la criminalité pour mieux la combattre, ceux-ci s'intéressent de près à Caserio, et mettent son cas en perspective avec ceux déjà étudiés par les savants ${ }^{57}$. Moins importante en 1932, cette science est moins sollicitée, d'où la quasi-absence de références médicales à cette catégorie de criminels.

Quant aux assimilations au régicide qui ne relèvent pas de la criminologie, on pourrait les expliquer par le besoin, face à un événement imprévu, de le relier à ce qui est déjà vécu, connu. Or, l'histoire de France est le premier lieu de mémoire dans lequel on se réfugie et il n'existe pas, en 1894, de précédent d'un assassinat de président de la République. D'où les références à ce que l'on juge comme équivalent: les tentatives d'attentats commises sur les chefs d'État précédents.

Cette analyse serait suffisante si les comparaisons s'établissaient avec le passé proche, ce qui est le cas pour la tentative d'Orsini; mais on évoque également Fieschi, Ravaillac et même Gustave III, ce qui témoigne que la mise en perspective avec le régicide renvoie à d'autres raisons plus profondes ${ }^{58}$. Plusieurs éléments en effet coexistent en 1894 et motivent cette lecture du crime. La forme du meurtre, tout d'abord: l'utilisation du poignard par Caserio ainsi que son intrusion dans la calèche présidentielle rappelle les stéréotypes du régicide et fonde ainsi bon nombre de comparaisons. On évoque le poignard, "arme de précision des régicides » ${ }^{59}$, qu'a utilisé Caserio, «en sautant sur le marchepied de la voiture, comme le fit Ravaillac avec Henri IV, dans la rue de la Ferronnerie $~^{60}$. L'attentat de Gorguloff ne renvoie guère pour sa part à cet imaginaire du régicide: l'utilisation du pistolet en fait un crime «moderne», de même que l'utilisation des photographies, largement diffusées, qui contribue à démythifier l'événement, en laissant moins de place à l'imagination, en offrant des faits une image brute, presque objective.

Ce sont également les mobiles du criminel qui, en 1894, amènent la mise en parallèle. Le fanatisme politique de Caserio est rapproché de celui de Clément, Ravaillac et Orsini ${ }^{61}$. L'existence $\mathrm{d}^{6}$ une motivation à connotation politique, la remise en cause du régime en place, est un élément capital dans l'assimilation au régicide; ainsi l'attentat de Perrin à l'encontre de Sadi Carnot en 1889 n'avait pas été considéré comme tel par la presse, car son auteur avait tiré à blanc afin d'attirer l'attention sur son sort (magasinier de la marine, il avait été désigné pour aller au

sortie de l'Opéra. Le 14 juillet 1922, Charles Bouvet tira deux coups de feu sur la voiture du préfet de police Naudin, croyant viser celle du président de la République.

57 Notamment avec le travail de Régis (1890). Les discours criminologiques sont essentiellement centrés sur la question de la psychologie du criminel. Si la presse évoque succinctement le livre de Régis, elle n'en précise pas le contenu. Cette omission est à lier avec l'enjeu pénal de la responsabilité de l'assassin. Ce point sera développé plus loin.

58 Ravaillac est l'assassin du roi Henri IV (14 mai 1610). Gustave III, roi de Suède, est mort assassiné en 1792 par un officier; Édouard Drumont dans La Libre Parole du 26 juin 1894 evoque Carnot «frappe d'un poignard en plein ventre au milieu d'une ville en fête, comme Gustave III par Inkorstroem".

59 Cette expression est reprise par Le Jour du 26 juin 1894 et Le Figaro du 26 juin 1894.

60 L'Autorité du 26 juin 1894

61 Saint Gilles (1894); Les Débats du 26 juin 1894 ; L'Autorité du 26 juin 1894 . Clément est l'assassin du roi Henri III le $1^{\text {ex }}$ août 1589. 
Sénégal) ${ }^{62}$. Si, à travers Carnot, c'est, comme nombre de ses «prédécesseurs», le régime que Caserio veut agresser, Gorguloff à l'inverse, en s'attaquant au poste présidentiel, ne cherche qu'à influer sur le cours des relations internationales. Dès lors, sa comparaison avec le régicide est plus délicate.

Enfin, et c'est sans doute là un des éléments les plus importants, c'est la personne visée qui constitue le dernier élément rattachant le «présicide» au régicide. On peut légitimement s'interroger sur l'influence de l'appartenance politique sur la perception du meurtre: les tenants de la droite et du monarchisme ne seraient-ils pas plus enclins à pratiquer cette assimilation? S'il est vrai que leur conception de l'autorité les y prédispose, force est de constater que lorsque l'identification au régicide est refusée, elle l'est par des journaux tant socialistes, radicaux que conservateurs, sympathisants boulangistes ${ }^{63}$. Qui plus est, la thèse du régicide est également développée par des journaux républicains tels que Le Petit Dauphinois Républicain, Le Jour, ou Le Petit Journal. En fait, cette évolution de la signification de l'assassinat entre 1894 et 1932 renvoie à la modification de la perception de la fonction présidentielle. À l'époque de la mort de Carnot, la figure du président est encore inaboutie, inachevée; elle hésite entre anciennes et nouvelles formes de souveraineté, d'autant que sa définition légale est rejetée au profit d'une pratique coutumière. Les voyages de Carnot en province, bien que réinvestis «d'une symbolique neuve, celle du lien citoyen ${ }^{64}$, rappellent les voyages de souveraineté des anciens monarques. Plus généralement, sa fréquente participation aux œuvres de charité et le souci de représentation dont il a su faire preuve tout au long de son mandat emprunte aux caractéristiques des fonctions royales et impériales. Ambivalence nécessaire, tant if est vrai que la population elle-même, jusque-là habituée à l'incarnation charnelle du pouvoir, ne pouvait que très difficilement se représenter sans transition le principe d'autorité de manière abstraite, immatérielle ${ }^{65}$. En 1932, les nouvelles formes de lien politique sont intégrées dans les esprits et la figure du président de la République a pu s'affranchir des anciens modèles politiques, construire sa propre spécificité, ce qui explique la comparaison entre présidents. Les éloges funèbres confirment cette évolution: si le modèle politique développé en 1894 renvoie parfois à la notion de prestige, de charisme (on souligne que Carnot est issu d'une lignée prestigieuse, qu'il avait une "nature d'élite ${ }^{66}$; on rappelle les titres dont il bénéficiait en France et à l'étranger), celui de 1932 insiste exclusivement sur la simplicité, l'humilité, l'idée de délégué temporaire.

62 La presse s'était alors empressée de minimiser l'attentat, qu'elle soit ou non hostile à Carnot. Le Matin du 6 juin 1889, par exemple, souligne qu' «il ne nous semble pas nécessaire de qualifier «attentat contre le président de la République «l'acte auquel s'est livré (...) un pauvre diable de magasinier».

63 Cf. Le Parti Ouvrier du 26 juin 1894; Le Rappel du 27 juin 1894; Le Gaulois du 25 juin 1894 et L'Intransigeant du 26 juin 1894.

64 D'après Mariot (1995, p. 34).

65 Pour certains, c'est d'ailleurs cette ambiguitté et ce poids particulièrement lourd de la fonction presidentielle qui ont motivé le crime. Cette analyse se retrouve tant dans les journaux socialistes, comme Le XIX $X^{\text {eme }}$ siècle du 27 juin 1894, que dans les journaux de la droite conservatrice: « Croyez-vous que l'assassin eut recherché M. Carnot, si le Parti Républicain n'eut commis (...) l'illogisme de lui donner, dans les cérémonies publiques, toute l'apparence d'un vrai monarque, ce qui est absurde sous une République ?» Écrit L'Autorité du 27 juin 1894. 
À la comparaison entre les présidents s'ajoute un second mode de représentation du crime totalement novateur en 1932: son assimilation au crime politique. Lors de l'évocation des précédents historiques, le nom de Gorguloff se trouve mêlé à ceux de Vaillant et de Villain ${ }^{67}$. En ce sens, l'assassinat du président de la République perd de sa spécificité: il n'est plus caractérisé par le statut particulier de sa victime mais par son appartenance, plus vaste, au personnel politique.

La mise en perspective du meurtre de Doumer avec celui de Jaurès, qui est la plus fréquemment usitée, est l'aboutissement d'une longue évolution contribuant à une perte d'exceptionnalité de la fonction présidentielle. Alors même que celle-ci, paradoxalement, avait été rehaussée par la mort de Carnot $^{68}$, les attentats dirigés contre les prédécesseurs de Doumer n'avaient guère contribué à signifier cette particularité du poste. Au contraire, tous ont semblé traduire sa perte d'importance: lorsqu'Émile Loubet échappe, le 30 mai 1905, à une bombe destinée à Alphonse XIII, c'est la volonté d'atteindre le roi d'Espagne et le comportement de ce dernier qui est au centre des récits, tandis que le président de la République est relégué au simple rôle accessoire de témoin oculaire. Bien que Bouvet, le 14 juillet 1922, ait déclaré avoir voulu tuer Millerand, on ne retient pas l'atteinte au président de la République et on se contente de juger une tentative homicide au sens large, quel qu'ait pu en être le destinataire éventuel ${ }^{69}$. La dernière agression directe en date précédant l'attentat de Gorguloff, loin de conférer un certain prestige au président de la République, a plutôt contribué à le ridiculiser: Séraphin Mattis, en tirant la barbe de Fallières le 25 décembre 1908, prête plus au rire qu'à la dramatisation ${ }^{70}$.

Surtout, l'attentat politique a, depuis, adopté de nouvelles formes. Jusqu'alors, sous les précédents régimes, presque exclusivement destiné aux titulaires de l'autorité, qu'ils soient rois, empereurs ou héritiers en titre comme le duc de Berry, il s'est depuis diversifié; on s'attaque désormais au personnel politique au sens large, ministres (attentat contre Freycinet), président du Conseil (attentat de Cottin contre Clemenceau du 19 février 1919) ou leader politique (assassinat de Jaurès). Et ici, la résonance du crime est tributaire du charisme des victimes plus que des attributions qui sont les leurs, comme en témoigne l'impact exceptionnel de l'assassinat de Jaurès et de l'attentat envers Clemenceau, pour lequel on retient plus l'atteinte à $l^{\prime}$ 'homme de la victoire qu'au président du Conseil ${ }^{11}$. L'attentat contre le président de la République perd donc de sa spécificité dans la mesure où l'attentat politique n'est plus limité à un seul homme, titulaire du pouvoir. Le meurtre du président de la République témoigne d'une atteinte au politique parmi tant d'autres, politique désormais perçu de manière diversifiée, et en ce sens adapté aux nouvelles institu-

67 Jeune nationaliste, assassin du leader socialiste Jean Jaurès le 31 juillet 1914 . Ce dernier prônait le pacifisme à la veille de la Première Guerre mondiale.

68 Cf. les assimilations au régicide et Le Matin du 26 juin 1894. Pour les journaux de droite, le fait que Carnot ait été victime d'un vrai attentat le place au même rang qu'un monarque, et en ce sens légitime l'assimilation au régicide.

69 Gazette des Tribunaux, 10-11 janvier 1919.

70 L'événement fait ainsi le bonheur des Camelots du Roi (militants royalistes) qui, pendant le mois de janvier 1909, vendront sur les boulevards un jouet mécanique en carton représentant Mattis en train de tirer la barbe du président, aux cris de «Le drame de la place de l'Étoile, tirez la barbichette ! 25 centimes seulement !» (APP Ba 1667).

7 Cf. les propos du lieutenant Mornet au procès lors de la séance du 14 mars 1919, in Gazette des Tribunaux du 16 mars 1919. 
tions républicaines. Le lien politique s'est en 1932 détaché de la notion de lien personnel, du concept de personnalisation du pouvoir, permettant ainsi une objectivation du crime.

Dès lors, l'assimilation au crime politique rend possible une autre parole sur l'événement. La perte de spécificité du crime explique en 1932 la prééminence de la figure de l'assassin au détriment de celle de la victime dans la presse; c'est, très vite, la personnalité de Gorguloff qui motive la plupart des articles, tandis qu'en 1894 le panégyrique du président défunt a occupé plus longtemps le devant de la scène. Surtout, le discours sur le crime s'objectivise. En 1894, il est largement tributaire de l'affect; les qualificatifs employés renvoient tous à une dimension morale: on parle de «l'abominable», «l'odieux attentat» commis par le «monstre» Caserio, dont on va même refuser de prononcer le nom, pour mieux manifester le dégoût à son égard. En 1932, ce type de discours existe toujours, mais cède progressivement la place à une vision plus distanciée des choses. La stigmatisation du criminel se fait moins marquée; Le Populaire va jusqu'à écrire que «la personnalité de Gorguloff nous indiffère; sa vie doit être classée parmi celles qui n'inspirent aucune sympathie $»^{72}$. D'une manière générale, le crime n'est plus défini par sa monstruosité, mais par sa réalité brute, technique: l'assassinat du président de la République en exercice.

L'assimilation au crime politique va, de plus, rendre enfin possible une interrogation rationnelle sur les mobiles de l'assassin. Même si le geste de Gorguloff reste contestable, illégitime, on cherche à le rapprocher d'une philosophie politique théorisée, argumentée. En s'interrogeant sur son appartenance communiste ou fasciste, on replace son acte, même s'il est fanatique, dans le cadre d'une pensée politique reconnue. $M^{e}$ Henri Géraud fondera d'ailleurs sa défense sur l'idée de passion politique, ainsi qu'il l'avait déjà fait 13 ans plus tôt pour Raoul Villain. Rien de tel en revanche avec Caserio pour lequel aucune allusion n'est faite à l' anarchisme comme système idéologique, idéal de vie: son geste est uniquement présenté comme un acte de haine, motivé par la soif de sang et l'impératif destructeur des libertaires, opérant ainsi l'amalgame anarchisme/terrorisme. Parallèlement, si les journaux réfutent l'hypothèse du fanatisme politique en 1932 c'est pour évoquer la folie comme élément explicatif du crime, et non la férocité et la cruauté comme en 1894.

La perception du crime s'étant émancipée de l'affect, la presse n'est alors plus unanime face au châtiment. Perçue en 1894 comme la juste expiation du crime, l'exécution de l'assassin n'est plus accueillie 38 ans plus tard qu'avec réticence et répugnance par la majeure partie de la presse, qu'elle soit de gauche ou de droite. Moins médiatisée, elle n'est plus décrite avec complaisance mais au contraire décriée, par opposition au spectacle des exécutions capitales (l'Action Française par exemple parle de «scène d'abattoir ») ${ }^{73}$, ou encore parce que, Gorguloff étant considéré comme un fou, sa condamnation à mort ne se justifie pas aux termes mêmes de la $\operatorname{loi}^{74}$.

Cette nouvelle lecture du crime s'oppose toutefois à celle, plus traditionnelle, qui en est faite par les autorités. Leur perception du meurtre demeure encore en 1932

72 Le Populaire du 23 août 1932.

73 L'Action Française du 15 septembre 1932; la même retenue se retrouve dans L'Intransigeant et dans Le Quotidien du même jour.

${ }^{74}$ Cf. Le Populaire des 11,14 et 15 septembre, LÈre Nouvelle et Le Peuple du 15 septembre 1932. La Ligue des Droits de l'Homme protestera également sur ce point et demandera l'internement du criminel. 
tributaire de l'affect. Le procureur général Matter, appelé à statuer sur le pourvoi en cassation de Gorguloff, croit nécessaire de signaler qu'il s'est «limité au droit pur, en essayant de faire taire (son) cour ${ }^{75}$; quant au procureur général Donat-Guigue, il regrette la disparition de la peine du parricide. L'absence d'objectivité se manifeste également lors du procès à travers la prise à partie moralisatrice de l'accusé ou encore l'appel à la xénophobie des jurés ${ }^{76}$.

Plus précisément, la manière dont celui-ci s'est déroulé témoigne de la reconnaissance de l'exceptionnalité du crime par les autorités. Sept magistrats ont été retenus pour siéger à la Cour au lieu des quatre habituellement requis, et c'est Eugène Dreyfus, pourtant non rattaché à la Cour d'Assises (il représente les intérêts de la France à la Cour Internationale de la Haye) qui a été choisi pour présider le procès, ce qui rappelle l'extraordinaire du crime. On retrouve, en 1932 comme pour 1894, une même volonté d'exemplarité de la part des autorités, qui se caractérise d'abord par la rapidité de l'instruction (d'une durée moyenne de 6 mois, celle de l'affaire Caserio sera de 40 jours, et d'un mois pour Gorguloff). En outre, on note aux deux époques des irrégularités de procédure flagrantes: initialement prévu pour les 25 et 26 juillet, le procès Caserio fut reporté en dernière minute aux 2 et 3 août par lettre du procureur général, afin que l'on puisse y appliquer les dispositions de la loi du 28 juillet réprimant les menées anarchistes, et ce au mépris du principe de non-rétroactivité de la loi; en 1932, les autorités judiciaires chercheront à prendre Gorguloff de vitesse pour qu'il ne puisse présenter son second pourvoi en cassation. On est en présence dans les deux cas d'une volonté de punir le crime à tout prix, et la sanction doit être à la mesure de l'exceptionnalité du crime: en 1894 et 1932, les deux procureurs généraux évoquent la nécessité du «châtiment suprême».

D'où ce refus réitéré de la folie du criminel, afin de le soustraire au jeu des circonstances atténuantes puisque, en vertu de l'article 64 du code pénal, «il n'y a ni crime ni délit si le prévenu était en état de démence au moment de l'action ou lorsqu'il a été contraint par une force à laquelle il n'a pas pu résister ». Tout comme la responsabilité de Caserio fut invoquée et affirmée sans que l'on puisse recourir au concours objectif d'experts psychiatres ${ }^{77}$, celle de Gorguloff sera établie, certes à l'issue d'une expertise médicale, mais partiale et catégorique: face aux signes apparents de démence, les experts officiels se contenteront d'évoquer les bizarreries ethniques des slaves ${ }^{78}$, et le parquet rejettera la demande de contre-expertise demandée par la défense.

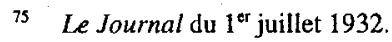

76 «Regardez-le (...) C'est un slave, mélange de rêve de mysticisme et de cruauté asiatique ». Propos du procureur Donat-Guigue reproduits in Le Quotidien du 28 juillet 1932.

77 Aucune expertise psychiatrique ne fut effectué sur Caserio, et le président des Assises ainsi que le procureur général s'efforcèrent, tout au long du procès, de souligner le caractère conscient et lucide du crime, en minimisant l'épilepsie supposée du père de l'assassin, et en insistant sur la préméditation du meurtre. Cette occultation de la folie de l'assassin se retrouve également dans la presse. L'unique parole criminologique à être publicisée fut celle d'André Lacassagne, seul savant autorisé à rencontrer l'assassin, et farouche partisan de la responsabilité. Quant à Lombroso et Régis, voyant dans l'acte de Caserio un acte d'aliéné, ils ne purent exposer leur opinion que dans les joumaux étrangers. Il est par ailleurs intéressant de noter que ces avis divergents ne seront publiés qu'en 1895 dans les revues criminologiques [Régis (1895)], alors que le livre de Lacassagne paraîtra lui dès 1894 [Lacassagne (1894)].

78 Pour le docteur Génil Perrin, la «mentalité particulière» de Gorguloff ne tient pas à «des causes pathologiques» mais à des «causes ethniques», c'est-à-dire à la «mentalité slave». 
Aucune disposition n'existant dans le droit pour qualifier l'assassinat du président de la République ${ }^{79}$, on retrouve également de la part des autorités, déterminées à assurer au crime un châtiment exemplaire, le même refus de l'assimilation pénale au crime politique, soustrait à la peine de mort depuis 1848 . Cette démarche était d'autant plus aisée que la notion même de crime politique n'avait jamais été définie par la loi. En 1894 c'était ainsi, respectivement à la théorie anarchiste dont se réclamait Caserio, dans la catégorie des «infractions sociales $»^{80}$ que l'on avait rangé le crime, l'excluant par conséquent de la catégorie du crime politique. C'est en 1932 la question de la qualification de l'assassinat du président de la République au sens large, quels que soient les motifs qui le portent, qui fut tranchée par un arrêt de la Cour de Cassation. Celui-ci faisait suite au pourvoi formé par Gorguloff après sa condamnation à mort stipulant qu' « en violation des articles 5 de la constitution du 4 novembre 1848 , 1er de la loi du 8 juin 1850 et 86 du code pénal, l'arrêt de la Cour d'Assises de la Seine avait appliqué la peine de mort à un crime dont le caractère politique ressortait de l'acte d'accusation et des termes mêmes de la déclaration du Jury ». L'appel fut rejeté le 20 août 1932 sous motif que «l'article 5 de la constitution (...) ne profite qu'aux crimes et aux délits politiques et non à l'assassinat qui, par sa nature et quelqu'en aient été les motifs, constitue un crime de droit commun ${ }^{81}$. C'était faire ainsi référence à la théorie juridique des infractions complexes, et à la prédominance des droits lésés ${ }^{82}$. Son geste pénalement relégué à un simple homicide, Gorguloff allait alors pouvoir payer de sa vie l'offense qu'il avait faite à l'État.

\section{CONCLUSION}

Bien que l'on soit en présence, en 1894 et 1932, du même fait brut, les deux assassinats ont donc eu un impact sensiblement différent. C'est que la perception du crime ne s'établit pas en fonction d'invariants immédiatement identifiables. Elle n'est pas, contrairement à ce que l'on pourrait imaginer, tributaire des formes institutionnelles du régime et de la définition technique du poste présidentiel mais dépend, comme nous l'avons vu, d'une série de facteurs plus complexes.

Toujours, le meurtre du président de la République est pensé en fonction d'autres morts tragiques. C'est véritablement une mémoire du régicide qui est mobilisée par le corps social en 1894, preuve que la transgression régicide s'inscrit dans l'imaginaire collectif, participe de la construction d'une mémoire commune. Si le meurtre s'inscrit dans l'histoire c'est, au delà de sa dimension traumatique, souvent en rai-

79 Avec l'avènement de la Troisième République, l'article 86 , sanctionnant l'attentat contre l'empereur et, accessoirement, la famille impériale, fut tacitement abrogé. Il faudra attendre un décret-loi du 29 juillet 1939 pour que l'on entérine définitivement sa suppression du code pénal. Pénalement, on considéra l'attentat contre le président de la République sur le même plan que l'atteinte à un individu ordinaire. Aussi, Caserio et Gorguloff furent tous deux jugés par la Cour d'Assises.

80 C'est ainsi qu'on appelait les infractions voulant ébranler l'organisation sociale indépendamment de la forme politique des États.

81 Reproduit in Garçon (1952, p. 415). L'arrêt stipule également que l'on doit considérer l'article 86 du code pénal comme tacitement abrogé par l'instauration de la Troisième République.

82 Les infractions complexes étaient des infractions constituées par un fait criminel unique à double effet, réunissant deux infractions. Or, on faisait appel, pour déterminer le statut de ces infractions, à la théorie de la prédominance des droits lésés, c'est-à-dire de l'assimilation automatique au droit commun si l'infraction lésait en même temps des intérêts privés et d'ordre politique. 
son du sens extrêmement lourd que le régime lui confere. Or l'on assiste bien, en 1894, à une instrumentalisation de la mort présidentielle. L'agression, pourtant jugée illogique quelques années plus tôt, va être récupérée et servir à la construction identitaire de cette République encore jeune et controversée. Alors même que les discours institutionnels insistent sur l'inutilité d'un tel crime et la pérennité du régime, cette mort dont on nie l'importance est exaltée, commémorée ${ }^{83}$. La liturgie politique, la martyrologie développée autour du corps de Carnot inscrit l'événement dans une dimension quasi-mythique, comme cela avait été le cas presque trois siècles plus tôt pour Henri IV. Mais les thématiques et les mises en scène sollicitées sont républicanisées. Carnot meurt en soldat en non en guerrier ${ }^{84}$; les signes de République et les drapeaux tricolores caractérisent le deuil. À travers le sens donné au meurtre du président par le régime en 1894 c'est la façon dont la Troisième République construit son identité, la manière dont elle pénètre et renouvelle les anciens rites de légitimation politique qui se manifeste.

Paradoxalement, l'identité de la Troisième République s'exprime aussi à travers le peu d'importance accordé à la mort de Doumer. Sa non-exploitation à des fins autres que partisanes marque sa faible incidence pour un régime parlementaire installé, établi.

Sacrifice s'inscrivant dans le combat pour la République en 1894, simple élément de la bataille électorale en 1932, le poids inégal que revêt le meurtre traduit surtout une évolution de la signification de «l'assassinat du président de la République» dans l'absolu pour le corps social. Perçu comme un régicide en 1894, il est représenté, 38 ans plus tard, comme un crime politique. Ce nouveau sens conféré au crime témoigne d'une modification en profondeur du rapport des citoyens à la Troisième République. L'assimilation au régicide atteste de ce que celui-ci s'établit, presque dix ans après la fondation de l'Etat républicain ${ }^{85}$, en fonction de schèmes mentaux correspondant aux régimes politiques précédents, d'anciens critères de représentation du politique. En 1932, le relatif désintérêt du corps social face au crime, relégué à un simple épiphénomène de la vie politique, son insertion dans la catégorie plus vaste du meurtre politique, témoignent quant à eux d'une culture politique nouvelle, que l'on peut définir par deux points majeurs. Elle est spécifique au régime - puisque, comme nous l'avons vu, le lieu de mémoire sollicité est la Troisième République, preuve que celle-ci s'est constituée une histoire, une mémoire propres. En outre, on peut y voir le signe de l'émergence d'une certaine "maturité » politique au sein de la population. C'est la première fois dans l'histoire de la France que l'assassinat ou la tentative d'assassinat du souverain/chef d'État perd toute spécificité, toute particularité. Cette nouvelle perception du crime transcende les cli-

83 «(..) Il convient de tirer de ce tragique événement la leçon qu'il comporte. D'abord, la stabilité de la République. Il peut dépendre d'un meurtrier de nous jeter dans la désolation, mais non de nous déconcerter ni de compromettre la République». Discours de M. de Mahy, vice-Président de la chambre des députés, aux funérailles de Sadi Carnot. Dans son message aux chambres, le nouveau président de la République, Casimir Perier, avait déjà souligné cette continuité des institutions: «L'acte de l'Assemblée nationale, assurant en quelques heures la transmission régulière du pouvoir, a ćté aux yeux du monde une consécration nouvelle des institutions républicaines » (Journal Officiel, Débats parlementaires, annales de la chambre des députés, séance du 3 juillet 1894, p. 678).

84 Le thème du souverain-chevalier ou du guerrier charismatique est en effet une constante des éloges politiques consécutifs aux attentats régicides en France de 1610 a 1858.

85 On prend ici pour base les lois constitutionnelles de 1875 instituant définitivement la République, et non sa proclamation par le gouvernement de défense nationale le 4 septembre 1870 . 
vages politiques, ce qui suppose qu'elle n'est pas relative à l'appartenance politique mais qu'elle dépend du rapport au lien politique, au politique au sens large. Ce dernier semble désormais être conçu non pas tant de façon personnelle, affective que comme une abstraction, une réalité immatérielle. À travers ce rapport plus objectif au crime se lit un rapport plus rationnel des individus au régime.

Ce véritable bouleversement des mentalités que l'on peut constater en 1932 connaît toutefois ses limites. À cette lecture moderne du crime par la société civile s'oppose la permanence du traitement juridique du régicide, tradition séculaire si ce n'est immémoriale. Là, la Troisième République s'efface devant l'État, et le crime n'est alors plus que l'atteinte à ce dernier, qu'il est nécessaire de punir à tout prix.

Dans la mesure où ses représentations le rattachent toujours à d'autres types de transgressions, régicide ou meurtre politique, l'on peut en dernier ressort souligner à quel point l'assassinat du président de la République, crime nouveau, ne semble pas avoir eu une identité originale, c'est-à-dire définissable par sa singularité inédite, personnelle. Cette caractéristique est-elle une spécificité française? Seule une étude comparative internationale pourrait y répondre. La mise en perspective avec l'exemple américain notamment serait riche d'enseignements. Si l'on peut retrouver outre-Atlantique la même exploitation politique de la mort tragique présidentielle (le corps défunt de Lincoln, transporté en train, fut ainsi exhibé dans tout le territoire par les autorités), qu'en est-il des représentations du crime sur plus long terme ? Comment le présicide est-il pensé dans ce «nouveau monde» à l'histoire relativement neuve, qui n'a jamais connu le régicide? A-t-il pu s'affranchir des anciens modes de définition traditionnelle de l'atteinte au souverain et bénéficie-t-il à ce titre d'une identité, d'une signification propres? Ou reste-t-il liê au crime politique, dans un État où les premiers attentats politiques individuels n'étaient pas spécifiquement présidentiels mais dirigés contre les divers membres du corps politique ${ }^{86} ? \ldots$

Karelle Vincent

16 rue Cavenne

69007 Lyon

E-Mail : Karellevincent@yahoo.fr

\section{RÉFÉRENCES}

Braud, P., La violence politique dans les démocraties européennes occidentales, Congrès de l'association française de science politique, Paris, l'Harmattan, 1993.

Bertol, G., Histoire d'un Français, Paris, 1899.

Cœuré, S., Monier, F., Le rouge, le blanc, le fou: Paul Gorguloff assassin du président Doumer en 1932, intervention au colloque «Régicide et meurtre de l'homme d'État. Histoires, formes, représentations», Université Paris X-Nanterre, ENS Saint-Cloud, Société pour l'histoire de la Justice, novembre 1995, inédit.

Fondation "Pour la Science». Centre International de synthèse. Inauguration du buste de Paul Doumer, le samedi 21 avril 1934, Paris, 1934, 48 pages.

${ }^{80}$ Indifféremment dirigés contre les sénateurs, les représentants au Congrès, les gouverneurs et les législateurs, ce n'est qu'à partir de la fin des années 1870 que les attentats se centreront prioritairement autour de la magistrature suprême, d'après Ford (1990, p. 496-497). 
Ford, F.L., Le meurtre politique, du tyrannicide au terrorisme, Paris, Presses Universitaires de France, 1990.

Garçon, E., Code pénal annoté, Tome I, Paris, Sirey, 1952 (nouvelle édition).

Harismendy, P., L'assassinat du président Sadi Carnot à Lyon, in Garnot, B., (dir.), Ordre moral et délinquance de l'Antiquité au XX $X^{e}$ siècle, Actes du colloque de Dijon, Dijon, Éditions Universitaires de Dijon, 1994, p. 357-365.

Harismendy, P., Sadi Carnot, L'ingénieur de la République, Paris, Librairie Académique Perrin,1995.

Lacassagne, A., L'assassinat du président Carnot, rapport médico-légal, Lyon, Storck, 1894.

Lacroix, B., Lagroye, J., (Dir.), Le président de la République. Usages et genèses d'une institution, Paris, Presses de la Fondation Nationale des Sciences Politiques, 1992.

La fin tragique du président Paul Doumer rapportée par deux reporters témoins oculaires. Nombreuses photographies. Compte rendu illustré des obsèques nationales, Paris, Librairie contemporaine, éditions G. Tallandier, 1932.

La revue des grands procès, Paris, 1933, tome 39.

Lavialle de Lameillère, Le président Carnot et ses funérailles au Panthéon, Paris, H. le Soudier, 1895.

Lehingue, P., La parole présidentielle. Travail de codification et définition du poste, in Lacroix, B., Lagroye J. (dir.), Le président de la République. Usages et genèse d'une institution, Paris, Presses de la Fondation Nationale des Sciences Politiques, 1992, p. 109140.

Maitron, J., Le mouvement anarchiste en France, Tome I, Paris, Gallimard, 1992 (réed.).

Mariot, N., Propagande par la vue. Souveraineté régalienne et gestion du nombre dans les voyages en province de Carnot (1888-1894), Genèses, 1995, 20, p. 24-47.

Monument de Carnot à Bordeaux. Discours prononcés à la cérémonie d'inauguration le 13 septembre 1896, Bordeaux, 1896.

Mousnier, R., L'assassinat d'Henri IV, 1964, Paris, Gallimard, 1992 (réed.).

Milza, P., Voyage en Ritalie, Paris, Éditions Plon, 1993.

Noiriel, G., Les ouvriers dans la société française, XIX $X^{e} X X^{e}$ siècles, Paris, Seuil, 1986.

Perrot, M., Fonctions de la famille, in Ariès, P., Duby, G., (Dir.), Histoire de la vie privée, Paris, Seuil, 1987, Vol. 4, p.105-120.

Picquet, M., Histoire d'un Français, Sadi Carnot, Paris, 1899.

Régis, E., Les régicides dans l'histoire et dans le présent, Lyon, A. Storck, 1890.

Régis, E., Le régicide Caserio, lettre à M. le Dr A. Lacassagne, Archives d'Anthropologie Criminelle, 1895, p. 59-71

Rémond, R., Les droites en France, Paris, Éditions Aubier, 1982.

Rétat, P., (Dir.), L'attentat de Damiens, discours sur l'événement au XVIII siècle, Lyon, Presses Universitaires de Lyon, 1980.

Saint Gilles, La vérité sur le crime de Caserio Santo, suivi d'extraits d'articles de François Coppée, Maurice Barrès, Henri Bauer, Paris, F. Brondert, 1894.

Trilogie. Heures sombres et carrefours dangereux, Angoulême, chez tous les libraires, 1897.

Van Kley, D.K., The Damiens Affair and the Unraveling of the Ancien Regime, 1750-1770, Princeton University, Princeton, N. J., 1983.

Villiers, A de, Paul Doumer parle, Paris, Tallandier, 1932. 